\title{
O desafio da produção de conteúdos noticiosos multimídia no cenário da convergência: a experiência dos repórteres do Diário Catarinense
}

\author{
AleXANDRE LENZI \\ Universidade Federal de Santa Catarina - lenzi.alexandre@gmail.com \\ Mestre em Jornalismo pela UFSC e subeditor de economia do Diário Catarinense
}

\begin{abstract}
Resumo
Antes mesmo de ser um consenso entre os teóricos, a adaptação de redações em busca de uma equipe multimídia vive experiências concretas. Acompanhando o ritmo dos grandes jornais nacionais, o Diário Catarinense, veículo do Grupo RBS com sede em Florianópolis, SC, aparenta estar disposto a rever as rotinas de produção em busca de adequação ao novo cenário do jornalismo digital. Este trabalho pretende mostrar como os repórteres da versão impressa do $D C$ estão lidando com este processo na prática e na teoria, apontando o que os profissionais reconhecem como exemplos de exercícios multimídia e os desafios enfrentados para sua execução no dia a dia. As entrevistas com 27 repórteres foram realizadas entre o segundo semestre de 2010 e o primeiro de 2011, seguidas por conversas com os profissionais que ocupavam na época os cargos de editores-chefe do jornal e do site. Entre os problemas apontados nesta fase de adaptação, aparecem a limitação de conhecimentos técnicos, a falta de tempo e a dificuldade de fazer mais de uma coisa simultaneamente. Como resposta, a direção do $D C$ anunciou uma rodada de treinamentos e a mudança para um novo prédio, planejado para integrar as redações on e off, no final de 2011.
\end{abstract}

Palavras-chave

Jornalismo digital. Reportagem multimídia. Hipermídia. 


\begin{abstract}
The effort of assimilating multimedia in the newsroom is having its results even before the consensus of theorists about it. Comparing with national newspapers, Diário Catarinense, a regional newspaper of RBS group, is also inclined to adapt the newsmaking routine according to the rules of digital journalism. This project intends to show how DCs reporters are dealing with this process. The objective is to verify what professionals recognize as multimedia aplications and to debate the challenges they have to overcome in their work routines. The interviews with 27 reporters have been done between the second half of 2010 and the first of 2011, followed by interviews with the editors of the newspaper and the site. Some examples of the problems identified at this stage of adaptation are limited technical knowledge, lack of time and trouble to do more than one thing simultaneously. In response, the direction of $D C$ announces a round of training and moving to a new building, planned to integrate the newsroom on-line and offline, until the end of 2011.
\end{abstract}

\title{
Keywords
}

Digital journalism. Multimedia report. Hipermedia.

Artigo recebido em 16/03/2012
Aprovado em 05/04/2012 
tecnologia está mudando a rotina das redações brasileiras. Em busca de
adequação ao novo cenário, grandes jornais testam na prática projetos que
visam uma aproximação entre as redações tradicionais e as equipes voltadas para os conteúdos das edições digitais. Veículos como O Estado de S.Paulo e Folha de S.Paulo, dois dos maiores jornais brasileiros, anunciaram mudanças em 2010 com grandes campanhas. Em Santa Catarina, o Diário Catarinense também vive um período de adequações práticas na integração entre jornalistas do impresso e do on-line.

O veículo do Grupo RBS com sede em Florianópolis é o jornal diário de maior circulação em Santa Catarina, com tiragem média de 40 mil exemplares - chegando a 65 mil exemplares nas edições de domingo, segundo dados do Instituto Verificador de Circulação (IVC). As mudanças na rotina dos jornalistas começaram em dezembro de 2007. Na época, foi lançado o diario.com. $b r$, abastecido com notícias produzidas pelos repórteres da versão impressa, material de agências e com conteúdo próprio da equipe recém-montada para o site. A apuração com recursos em mais de uma frente transformou-se em um exercício novo. A proposta era garantir recursos diferenciados para a versão on-line da reportagem que seria publicada também em papel.

O principal objetivo deste trabalho é identificar como as novas práticas adotadas pelos jornalistas do $D C$ podem ser enquadradas diante dos conceitos de multimidialidade e hipertextualidade apresentados por Marcos Palacios (2003), profissional da área de pesquisa e ensino de novas tecnologias de comunicação. $O$ pesquisador aponta a multimidialidade como a convergência dos formatos das mídias tradicionais (imagem, texto e som) na narração de um fato jornalístico numa situação de agregação e complementaridade; enquanto a hipertextualidade é definida como o recurso que possibilita a interconexão de textos através de links, para vários módulos da notícia e para elementos multimídia, outros sites e arquivos sobre o assunto.

É importante aqui fazer uma diferenciação conceitual do termo multimídia do rótulo de hipermídia, este último comumente apontado como um passo à frente do primeiro. Segundo Roger Laufer e Domenico Scavetta (1997, in GOSCIOLA, 2003, p 
7), hipermídia é o conjunto de meios que permite o acesso simultâneo a textos, imagens e sons de modo interativo e não-linear, possibilitando fazer links entre elementos de mídia, controlar a própria navegação e, até, extrair telas, imagens e sons cuja sequência constituirá uma versão pessoal do usuário. Características estas ainda não presentes no conceito multimídia defendido por Palacios (2003). A pesquisa realizada busca perceber como os próprios repórteres do $D C$ associam seus trabalhos com estes conceitos.

Com sede em Florianópolis, a redação do $D C$, segundo dados fornecidos pelo próprio jornal, em julho de 2010, conta com 110 profissionais, sendo 27 repórteres oito na editoria de Geral e Polícia, quatro no Esportes, três na Economia, três na Política, quatro na Variedades e cinco nas sucursais localizadas em Chapecó, Lages, Criciúma, Tubarão e Joaçaba. No quatro total da redação, estão inclusos editores, subeditores, colunistas, revisores, ilustradores e um chargista, fotógrafos, diagramadores e auxiliares de redação, além da equipe própria do diario.com.br - composta por 16 pessoas, entre editor, subeditores, redatores, assistentes de conteúdo e web designers.

Dos 27 repórteres, 22 foram entrevistados pessoalmente e cinco (os das sucursais localizadas fora de Florianópolis) por telefone. Os depoimentos foram coletados entre o segundo semestre de 2010 e o primeiro semestre de 2011. Cada entrevista seguiu um roteiro previamente elaborado. Foram entrevistados, ainda, o editor-chefe do Diário Catarinense, Nilson Vargas; o editor-chefe de internet do Grupo RBS em SC, responsável pelo diario.com.br, Marcelo Fleury; e a diretora de internet do Grupo RBS, Marta Gleich. As duas primeiras entrevistas foram realizadas pessoalmente e, a última, por telefone, todas em junho de 2011.

\section{Uma renovação de conceitos e de linguagem}

Dos 27 repórteres, 16 são mulheres $(60 \%)$ e 11 são homens $(40 \%)$. Todos são formados em Jornalismo e 10 têm alguma especialização (37\%), sendo que destes oito são na área de Comunicação e dois nas linhas de Educação e Sociologia. A maioria, 17 
repórteres $(63 \%)$, tem carga horária de oito horas, sendo uma de intervalo obrigatório. Nestes casos, o contrato é o regular de cinco horas diárias com duas horas-extras fixas por dia. Os outros 10 repórteres (37\%) têm carga horária de cinco horas ao dia.

Pode-se considerar o grupo jovem. São 16 repórteres (60\%) com idade entre 25 e 35 anos e outros três (11\%) com até 25 anos. A maioria, 16 repórteres (60\%) trabalha no Diário Catarinense há menos de cinco anos. Outros seis $(22 \%)$ estão na redação do $D C$ em um período entre 10 e 15 anos.

Pelo menos conceitualmente, os repórteres do $D C$ parecem entender a reportagem multimídia dentro da proposta de Palacios. Dos 27 entrevistados, 26 (97\%) conseguiram apresentar um conceito que se aproxima do defendido pelo pesquisador. A ideia básica é de que a reportagem multimídia é aquela que é feita já pensada para diferentes meios, além do escrito, com produção de conteúdos como vídeos, links e infográficos. "É uma reportagem com vários suportes, que pode ter infografia, áudio e vídeo para complementar o texto da matéria e facilitar o trabalho para os leitores", explica um entrevistado. Para outro, pode ser considerada multimídia "a reportagem que chama os leitores para o computador, oferecendo mais texto do que foi publicado na versão impressa, mais fotos ou vídeos".

Neste grupo, também já aparece uma preocupação de que os diferentes meios usados tenham entradas independentes e ao mesmo tempo complementares. Ou seja, que não sejam repetitivas. Por exemplo, que o vídeo não reproduza exatamente o mesmo conteúdo que o texto. "Só colocar um texto no pé da matéria impressa chamando para um vídeo no on-line que mostra a mesma coisa não é multimídia. É preciso pensar numa forma de integração dos meios", explica um repórter. "Vídeo, som e texto: tudo tem que ser relevante para matéria", complementa outro.

Apenas um repórter (3\%) não apresentou um conceito para a reportagem multimídia, por entender que este se encontra em processo de formação. Um conceito de hipermídia, no entanto, foge ao entendimento da maior parte da equipe do jornal catarinense. Apenas dois (7\%) apresentaram definições para o termo, reconhecendo o 
papel do leitor na condução e até mesmo construção da forma de apresentação da narrativa. "É quando a reportagem permite ao leitor ir a vários lugares, conduzindo a leitura pelos links para outros conteúdos complementares", define um deles.

A convergência entre redações impressas e on-line também aparece como um caminho a ser concretizado em breve, na opinião dos repórteres do $D C$. Dos 27 entrevistados, 22 (82\%) acreditam que esta é a tendência a ser seguida. A estrutura da equipe, no entanto, ainda precisa ser repensada, defendem. "Acredito na convergência, mas as redações precisam de mais estrutura, de mais retaguarda, mais equipamentos, melhores salários e menos demanda", avalia um dos entrevistados. "A integração das redações é possível, mas com trabalho em equipe. Não com uma pessoa tendo que fazer tudo sozinha", complementa outro repórter. A preocupação com uma "sobrecarga" de trabalho também aparece entre os quatro (15\%) que ainda não sabem se este é realmente o caminho a ser seguido pelas redações. O único entrevistado (3\%) que não acredita na proposta de convergência, justifica sua postura com a defesa de que é preciso investir em repórteres impressos de qualidade, profissionais que se dedicarem exclusivamente ao meio de papel, produzindo "textos diferenciados e de grande qualidade".

O editor-chefe de internet do Grupo RBS em Santa Catarina, Marcelo Fleury (2011), reconhece que apesar de a convergência das redações on-line e impressa dentro do próprio Diário Catarinense buscar resultados concretos, o modelo ideal ainda está em estudo. "Sabemos que tem que integrar, existem vários modelos de integração sendo testados em jornais de todo o mundo e estamos buscando um para o $D C$. Duas coisas facilitam o processo no nosso caso. A primeira é a pré-disposição das chefias. Eu tenho origem no impresso e tenho convicção de que a gente tem que integrar, de que não pode mais ter um repórter na bancada do on-line e outro na da Geral. A gente tem que diluir o núcleo on-line em cada editoria do impresso e chamar toda a redação para participar do processo, garantir que todo mundo deve estar pronto para publicar sua matéria factual agora, nas duas plataformas (papel e on-line). Outro ponto que favorece o $D C$ é que nós 
Estudos em Jornalismo e Mídia - Vol. 9 N I - Janeiro a Junho de 2012 ISSNe 1984-6924

vamos mudar de prédio ${ }^{1}$. A parte mais difícil é convencer toda a redação a comprar essa ideia".

\section{Uma renovação de rotina}

O que exige muita competência para ser feito em um único meio - impresso, televisivo, radiofônico ou digital - torna-se ainda mais difícil quando se exige do jornalista atuação em mais de uma frente. Lourival Sant'Anna (2008) acredita que uma sobrecarga de tarefas e de preocupações com aspectos técnicos, por mais simplificadas que sejam as operações dos novos aparelhos digitais, pode afetar a qualidade na apuração jornalística. Diante deste quadro, a alternativa não é desistir de uma produção multimídia, mas investir na formação de um novo perfil de jornalistas, no qual o individualismo e o protagonismo cederiam algum espaço para o trabalho em equipe. "O trabalho de apuração da reportagem, como empreitada solitária, fortemente marcada por talentos pessoais que funcionam como marcas distintivas aliadas ao nome de um profissional, perderia parte de seu papel" (SANT'ANNA, 2008, p 23). Ramón Salaverría e Samuel Negredo (2009) também reforçam esta necessidade de fortalecer o trabalho em equipe nas novas redações, diante das produções multimídia.

Apesar do cenário de incertezas, os repórteres do Diário Catarinense, em sua maioria, estão otimistas em relação ao futuro do jornalismo impresso. Apenas três $(11 \%)$ dos 27 entrevistados, acreditam no fim do jornal impresso. Mas entre os 24 (89\%) que acreditam que o jornal impresso continuará existindo, seis colocam uma necessidade de "reinvenção" como condição para o meio se manter. Entre as medidas necessárias para esta transformação, os entrevistados apontam características como reportagens mais interpretativas e mais aprofundadas e um elevado padrão de texto.

Um fator a ser destacado é o histórico destes profissionais no exercício do jornalismo impresso, antes mesmo de iniciar as atividades no Diário Catarinense. Dos 27 entrevistados, 18 (67\%) sempre trabalharam com jornalismo impresso.

Com a inauguração do diario.com.br, a maioria dos repórteres passou a experimentar as novas ferramentas. Antes, apenas cinco (18\%) tinham blogs 
particulares, enquanto os outros $(82 \%)$ não tinham usado esse recurso ainda. No diario.com.br, 19 repórteres (70\%) têm ou tiveram blogs - sendo que 15 são fixos e quatro foram temáticos, abordando a cobertura de viagens internacionais ou eventos esportivos - e apenas oito (30\%) ainda não usam a ferramenta no jornal.

Entre quem já criou os blogs, predomina a publicação de diferentes mídias. Dos 19 repórteres que têm ou tiveram blogs no diario.com.br, 11 afirmam que, além de textos, já fizeram também fotos e vídeos, seja com aparelhos celulares ou filmadoras portáteis. Entre os outros oito, a publicação de texto ainda é o único recurso utilizado.

Os primeiros exercícios em coberturas multimídia também já foram realizados. Dos 27, 26 (93\%) realizaram alguma prática voltada a gerar conteúdo complementar para a matéria impressa no site do diario.com.br. O único que não fez, alega falta de interesse pessoal como justificativa. Vale ressaltar que o Diário Catarinense foi a primeira experiência de praticamente todos os repórteres nessa área. Entre os 26 que produziram algo para o diario.com.br, apenas dois já haviam experimentado o exercício de reportagem multimídia antes de entrar no $D C$ - um deles ainda como atividade da faculdade e, o outro, como estágio em um site de notícias.

Entre as atividades citadas pelos repórteres, a mais comum é a produção de vídeos paralelamente a apuração para a reportagem impressa. São vídeos com depoimentos complementares ou com bastidores da cobertura. Dezessete repórteres afirmam que filmaram os próprios vídeos, seja com o aparelho celular ou com a filmadora portátil. E a edição ficou sob responsabilidade da equipe do on-line. E 12 também organizaram a produção dos vídeos, mas contaram com o apoio dos assistentes de conteúdo do diario.com.br ou dos fotógrafos para realizar as filmagens.

Em alguns casos, o mesmo repórter participou das duas situações - filmando e também produzindo o vídeo. Outros exercícios citados foram o levantamento de informações detalhadas para a produção de infográficos animados, a produção de imagens para galerias on-line e a cobertura de eventos pelo método de transmissão 
minuto a minuto. Neste último caso, o repórter fica abastecendo o site, direto do local do evento, com informações em tempo real.

Os exercícios multimídia têm surgido em coberturas do dia a dia. Em apenas um dos casos relatados, a pauta já nasceu com a pretensão de ser uma grande reportagem multimídia, com conteúdo de destaque tanto no impresso quanto no site.

Entre as dificuldades para realizar esses primeiros exercícios multimídia, os repórteres citam, principalmente, a limitação de conhecimentos técnicos para operar os equipamentos e garantir um material final de qualidade (problema citado por sete repórteres), falta de tempo (citado por seis repórteres) e a dificuldade de fazer mais de uma coisa ao mesmo tempo (também citado por seis entrevistados). Alguns relatos apontam que produções de vídeos chegaram a ser descartadas porque o material final não atendia as qualidades mínimas exigidas pela equipe do site.

Outros apontam que a preocupação com o vídeo acabou prejudicando o trabalho também para o impresso. "Quando ligava a filmadora, o entrevistado perdia a espontaneidade. E isso atrapalhava o rendimento para a matéria impressa", reclamou um entrevistado. "O mais difícil foi ter que fazer duas coisas ao mesmo tempo. Quando estava gravando, às vezes queria anotar algo e não dava. Faltavam mãos para lidar com câmera, microfone e bloquinho", acrescentou outro. "Fazer o vídeo junto com a entrevista para o impresso atrapalha. E não tem lógica fazer uma entrevista para o impresso e depois pedir para o entrevistado repetir o que já disse para, então, gravar o vídeo", complementa um terceiro. Este último, no entanto, diz que quando o trabalho de filmagem consiste em apenas captar as cenas de bastidores, fica mais fácil. E quando alguém da equipe do on-line vai junto, "o trabalho funciona bem".

O fator tempo também pesa na produção. Entre os 27 repórteres entrevistados, 19 (70\%) afirmam que a atual jornada prejudica a produção de conteúdo para o site, enquanto oito (30\%) afirmam que estão conseguindo conciliar os dois meios sem grandes dificuldades. Considerando apenas os repórteres com jornada de cinco horas por dia, o percentual daqueles que apontam dificuldades aumenta para $80 \%$ (oito dos 10 
jornalistas deste grupo). Logo, se levarmos em conta exclusivamente o repórteres de jornada de oito horas, o índice dos que estão com dificuldades cai para 65\% (11 dos 17).

O editor-chefe do $D C$, Nilson Vargas (2011), lembra que a preocupação com as limitações de produtividade na jornada de cinco horas é mais antiga do que a discussão sobre a produção multimídia. "Na redação monomídia, a gente já desenvolveu uma estrutura secular para ver o que cabe na minha jornada. Agora, o desafio é agregar a isso o perfil de produção multimídia". Ele ressalta que o importante é perceber que a ideia não é fazer com que uma pessoa assuma todas as etapas da produção nas diferentes mídias. "Se eu tenho uma pauta especial, que vai ser impressa no papel e publicada no meio on-line, eu preciso achar um tempo para pensar ela de maneira multimídia, mas pensar em equipe, em alguém para produzir o conteúdo, em alguém para editar o conteúdo on-line, enquanto outra empacota o produto no papel", aponta.

Vargas reconhece que o modelo ideal das novas redações ainda está sendo discutido. O caminho que ele identificou até agora consiste em as editorias temáticas passarem a ter atribuições offline e on-line. No $D C$, esta mudança implicaria em o corpo de repórteres do diario.com.br passar a integrar as diferentes editorias do jornal impresso. "Mas aquele que for do on-line para o impresso, não seria mais uma pessoa do on-line dentro da editoria, mas mais um repórter da editoria. São esforços para que as editorias ganhem estrutura para dar conta de suas atribuições on e off. E o núcleo online seria o grupo de editores de capa. E talvez tenha que existir ali uma reserva para produções especiais on-line", avalia. Os estudos dentro do Diário Catarinense estão avançando com a meta de implantar esta mudança ainda em 2011, aproveitando a mudança de endereço da sede do jornal, anunciada para o segundo semestre deste ano.

\section{Uma renovação profissional}

O potencial dos recursos multimídia para a reportagem jornalística, evidenciado pelo debate teórico, encontra um desafio prático: o treinamento dos profissionais para o exercício de funções com as quais não estavam acostumados. Um profissional cada vez mais polivalente parece ser a exigência do mercado. 
Ramón Salaverría e Samuel Negredo (2009) lembram que as mudanças não tratam apenas da tecnologia, mas também do ambiente de trabalho e da visão dos profissionais. E todo esse processo exige o envolvimento de toda a equipe. Um complicador apontado é a resistência à mudança por parte dos próprios repórteres, especialmente os mais veteranos. Os diretores do Grupo RBS entrevistados para esta pesquisa apresentam um discurso valorizando o profissional aberto às novas ferramentas da reportagem multimídia, mas também concordam entre si quando defendem que não vai ser um mesmo profissional que fará todo o trabalho sozinho. Para eles, reportagem multimídia é um exercício em equipe.

A diretora de internet do Grupo RBS, Marta Gleich (2011), reconhece que o treinamento em diferentes frentes facilita todo o processo de integração das redações. Ela defende que o importante é o profissional estar disposto a lidar com as novidades. "A pessoa não precisa ser um expert em vídeo e ter o melhor texto do mundo. Mas tem que estar aberta e preocupada com o novo cenário", afirma. O editor-chefe do $D C$, Nilson Vargas (2011), afirma que, na busca por novos profissionais para a redação, as premissas do jornalismo não mudaram. Para ele, o repórter, independentemente do meio, tem que saber apurar, ter faro para a notícia, saber quando a notícia está completa. "A mudança talvez esteja em como traduzir, como empacotar a informação. Aí é que começamos a enxergar essa mudança, nossa expectativa é de que o profissional tenha maior versatilidade, desenvolva mais formas de expressão. Mas isso não significa que ele precisa dominar todas as mídias profundamente".

Os repórteres do Diário Catarinense reconhecem que o cenário atual exige mudanças na profissão de jornalista, mas esta preocupação ainda não despertou ações práticas. Quando questionados sobre como pretendem se manter competitivos, como repórteres, neste quadro onde o meio digital ganha cada vez mais espaço, oito entrevistados (30\%) afirmam que não sabem quais serão seus próximos passos. "Eu sei que vou ter que fazer algo para me preparar para isso. Mas ainda não sei o que. Por falta de tempo, vou postergando", responde um dos entrevistados. 
Outros seis (22\%) jornalistas do $D C$ afirmam que pretendem voltar para a academia, para cursos de especializações ou mestrados. "É necessário estudar para tentar entender o novo cenário", responde um dos integrantes deste grupo.

A maioria, nove repórteres (33\%), no entanto, acredita que vai conseguir se preparar para as mudanças com a vivência da nova rotina dentro do próprio jornal. "A preparação é no dia a dia mesmo. Jornalismo sempre será falar com as pessoas e contar o que elas disseram. Isso não muda. O resto é acompanhar as modas do momento", defende um dos que descartam preparações externas ao jornal.

Há também, quem se recuse a vivenciar essa mudança de perfil profissional. Apontando desinteresse pelo exercício multimídia da função, um dos repórteres diz que já pensa em trocar de profissão, abandonando o jornalismo diário por uma carreira literária. Outro diz que pretende trabalhar com revistas. E dois afirmam que se preparam de forma autônoma lendo bastante sobre o assunto.

Embora a maioria aponte buscar um preparo na própria redação, os mesmos entrevistados afirmam que, por enquanto, ainda falta treinamento interno. Dos 27 repórteres, $24(89 \%)$ afirmam que não tiveram qualquer treinamento dentro do jornal para usar os equipamentos disponíveis - computadores portáteis, placas de internet $3 \mathrm{G}$, celulares com máquina fotográfica e filmadora, gravadores e filmadoras de pequeno porte. Os três $(11 \%)$ que tiveram algum treinamento resumem o mesmo a uma breve orientação antes de usar o material pela primeira vez.

A falta de treinamento também é evidente quando o assunto é cobertura multimídia. Dos 27 entrevistados, 19 (70\%) afirmam que não tiveram qualquer preparo formal, seja no $D C$ ou ainda na faculdade, para realizar este tipo de produção jornalística. "O aprendizado é dando a cara para bater", resume um repórter. Entre os oito $(30 \%)$ que passaram por um treinamento, todos apontam que o mesmo foi ainda na faculdade ou em especializações voltadas para o jornalismo digital. Mas o mais comum nestes casos foi um treinamento essencialmente teórico. 
O editor-chefe do DC, Nilson Vargas (2011), anunciou uma série de novos treinamentos. Serão duas linhas de atuação: uma envolve a Escola de Produtos, do Grupo RBS, criada em 2011, para treinar profissionais de diferentes áreas das redações dos jornais, sites, emissoras de rádio e de televisão de $\mathrm{SC}$ e do RS. As primeiras turmas começaram em julho de 2011, voltadas para o treinamento de gestão de pessoas e visão multimídia. A segunda linha de atuação prevê o treinamento interno dos profissionais da redação do Diário Catarinense. Os editores participarão de workshops para estimular a cultura da convergência, enquanto repórteres participarão de rodízios entre as equipes do jornal impresso e do diario.com.br.

\section{Conclusões}

Diante do crescimento diário da internet, as redações dos jornais impressos passam por um período de turbulência e há mais questões em aberto do que rotas certeiras. Mas quem esperar por um modelo pronto para a adaptação ao novo cenário de convergência, corre o sério risco de ficar defasado. É preciso se adaptar à plataforma multimídia: este é um caminho que não tem mais volta. Isso é fato. Quando e como fazer a adaptação, no entanto, são perguntas que ainda aguardam respostas.

O fato de o Diário Catarinense fazer parte do Grupo RBS, uma empresa multimídia, favorece a mudança, uma vez que os gestores do jornal impresso podem buscar nas empresas irmãs - emissoras de rádio e de televisão, além de sites - um pouco da realidade de quem trabalha com outras mídias. A troca de experiências ajudaria a desmistificar a ideia de que a reportagem multimídia é um bicho de sete cabeças, que, além de difícil de ser executada, faz o repórter trabalhar muito mais.

Há, cada vez mais, o reconhecimento de que reportagem multimídia é um trabalho de equipe, e não a estereotipada ideia de um repórter saindo para a pauta com caneta e bloco de papel, gravador, filmadora e máquina fotográfica. Talvez isso até possa existir em casos isolados, mas alguém que garanta a qualidade necessária em todas as mídias em uma mesma produção é algo distante da atual realidade das redações 
brasileiras. Os gestores do $D C$, embora busquem incentivar o exercício da produção multimídia, reconhecem que um repórter que faz tudo não é o caminho a ser seguido.

A empresa deve contribuir com o treinamento para suprir as necessidades de adaptação. Mas o repórter com um olhar mais amplo do mercado não deveria esperar apenas esta opção interna como alternativa para se qualificar para o novo cenário. No entanto, entre os repórteres do Diário Catarinense, apesar do consenso de que aqueles que continuarem trabalhando exclusivamente com produção para a mídia impressa tendem a perder espaço no mercado de trabalho, há certa inércia na hora de buscar a preparação necessária de forma autônoma.

O que se percebe é uma carência tanto de um debate conceitual como de um exercício prático dos novos recursos. E apesar do discurso de que é possível aprender a usar as novas ferramentas na prática - o que até pode, sim, ser uma verdade, mas não precisa ser a regra - o treinamento acelera a adaptação e potencializa as chances de produzir um material de maior qualidade. No melhor dos mundos, esse treinamento viria previamente à produção de conteúdos reais para os jornais, como se fosse uma fase de testes e experimentações. Mas um treinamento em paralelo ao trabalho diário, com os primeiros exercícios ocorrendo na prática do dia a dia, também é viável.

O foco desta pesquisa voltou-se para os repórteres. Mas as entrevistas com os gestores da redação do Diário Catarinense e com os próprios repórteres evidenciaram também o papel fundamental que os editores de área têm neste novo quadro multimídia. O repórter precisa ter o interesse e o devido treinamento para usar os novos recursos. Mas, para isso, precisa de alguém que estabeleça prioridades, reconhecendo e dividindo a jornada de trabalho entre as tarefas exclusivamente direcionadas para o jornal impresso e aquelas que precisam de um tempo extra para garantir conteúdo adicional para o site. Ou seja, o editor deve embarcar no discurso - e na prática - multimídia.

Esse processo de adaptação precisa ser realizado em meio a constantes revisões, porque a sobrecarga de trabalho em qualquer um dos níveis pode comprometer a qualidade do trabalho final. Uma nova pesquisa, com as reformulações anunciadas 
pelo $D C$ já em vigor, poderá demonstrar se essa mudança passa exclusivamente por repensar rotinas e tarefas ou exige também um maior quadro de recursos humanos. A proposta é de que o cenário ideal uniria esses dois aspectos.

Em junho de 2011, foi anunciado que a redação do Diário Catarinense seria transferida do atual prédio, no bairro Itaguaçu, parte continental de Florianópolis, para uma nova estrutura, no bairro Saco Grande, na parte insular da cidade. A mudança da estrutura física da redação, junto a de toda equipe administrativa e comercial do DC, ocorreu em novembro.

\section{Referências bibliográficas}

BRIGGS, Asa; BURKE, Peter. Uma história social da mídia: de Gutenberg à internet. Rio de Janeiro: Jorge Zahar Editor, 2004.

CARDOSO, Gustavo. A mídia na sociedade em rede. Rio de Janeiro: Editora FGV, 2007.

GOSCIOLA, Vicente. Roteiro para as novas mídias: do cinema às mídias interativas. São Paulo: Editora Senac, 2003.

JENKINS, Henry. Cultura da convergência. São Paulo: Aleph, 2008.

MEYER, Philip. Os jornais podem desaparecer? São Paulo: Contexto, 2007.

PALACIOS, Marcos; MACHADO, Elias. Modelos de jornalismo digital. Salvador: Calandra, 2003.

PALACIOS, Marcos. Jornalismo on-line, informação e memória: apontamentos para debate. In: Fidalgo, Antonio; Serra, Paulo (Org.). Jornalismo On-line: informação e comunicação on-line. Covilhã: Universidade da Beira Interior, 2003.

SALAVERRÍA, Ramón; NEGREDO, Samuel. Integrated journalism - Media convergence and newsroom organization. Barcelona: Editorial Sol 90, 2009.

SANT'ANNA, Lourival. O destino do jornal - A Folha de S.Paulo, O Globo e O Estado na sociedade da informação. Rio de Janeiro: Record, 2008.

\section{Entrevistas:}

FLEURY, Marcelo. Marcelo Fleury. Depoimento (17 de junho de 2011). Entrevistador: Alexandre Lenzi. Entrevista concedida para elaboração de dissertação.

GLEICH, Marta. Marta Gleich. Depoimento (6 de junho de 2011). Entrevistador: Alexandre Lenzi. Entrevista concedida para elaboração de dissertação.

VARGAS, Nilson. Nilson Vargas. Depoimento (13 de junho de 2011). Entrevistador: Alexandre Lenzi. Entrevista concedida para elaboração de dissertação. 